\title{
As engrenagens da saúde na terceira idade: um estudo com idosos asilados*
}

\author{
HEALTH IN OLD AGE: A STUDY WITH INSTITUTIONALIZED ELDERLY
}

LOS ENGRENAJES DE LA SALUD EN LA TERCERA EDAD: UN ESTUDIO CON ANCIANOS ASILADOS

\author{
Luana Cardoso Pestanaํㅜ Fátima Helena do Espírito Santo ${ }^{2}$
}

\section{RESUMO}

Diante do envelhecimento demográfico, as instituições asilares emergem como uma alternativa de suporte social para atenção à saúde do idoso. 0 estudo objetiva descrever a situação de saúde do idoso no cenário asilar e identificar como eles percebem sua saúde. Estudo qualitativo cuja coleta de informações envolveu observação participante e entrevistas semiestruturadas com 17 idosos em um asilo localizado no município do Rio de Janeiro. Os resultados evidenciaram que esses idosos entendem a própria saúde como satisfatória, estabelecendo relação com a ausência de dor, desconforto físico, sensação de segurança proporcionada pela vivência na instituição. Por outro lado, as preocupações relativas a dores e sofrimentos, decorrentes das perdas naturais, pelo distanciamento da família, sentimentos de solidão e abandono, foram condições associadas ao aparecimento de doenças. Concluiu-se que o fato social asilamento configurou-se principalmente pelo abandono, constituindo-se no seu principal motivo, o que vem influenciando diretamente as condições de saúde desta população.

\section{DESCRITORES}

Saúde do idoso institucionalizado. Promoção da saúde. Instituição de longa permanência para idosos.

\begin{abstract}
In the face of demographic aging, shelter institutions have an outstanding role as an alternative of social support in the attention for the health of the elderly. This study was aimed at describing the health condition of the elderly within the wide picture of old folks homes and identifying how the elderly perceive their own health. It is a qualitative study for which data was collected through participative observation and half-structured interviews with 17 elderly living in an old folks home in Rio de Janeiro. The results showed that the elderly see their health as satisfactory because there is no pain, no physical discomfort and they have a feeling of security provided by the fact that they live in the institution. On the other hand, concerns related to aches and suffering deriving from natural losses, distance from the family and feelings of solitude and abandonment were conditions associated to the occurrence of diseases. It was concluded that the social fact of living in an old folks home is characterized mainly as an abandonment, which has a direct impact on the health conditions of this population.
\end{abstract}

\section{KEY WORDS}

Health of institutionalized elderly.

Health promotion.

Homes for the aged.

\section{RESUMEN}

Frente al envejecimiento demográfico, las instituciones de asilo emergen como una alternativa de soporte social para la atención a la salud del anciano. El estudio tiene como objetivo describir la situación de salud del anciano en el escenario asilar e identificar cómo es que ellos perciben su salud. Se trata de un estudio cualitativo cuya recolección de informaciones involucró observación participante y entrevistas semi-estructuradas realizadas a 17 ancianos en un asilo localizado en el municipio de Rio de Janeiro. Los resultados evidenciaron que esos ancianos entienden su salud como satisfactoria, estableciendo relación con la ausencia de dolor, disconfort físico, sensación de seguridad proporcionada por la vivencia en la institución. Por otro lado, las preocupaciones relativas a dolores y sufrimientos, derivado de las pérdidas naturales, por el distanciamiento de la familia, sentimientos de soledad y abandono, fueron condiciones asociadas a la aparición de enfermedades. Se concluye que el hecho social aislamiento se configuró principalmente por el abandono, constituyéndose en su principal motivo, lo que viene influenciando directamente en las condiciones de salud de esta población.

\section{DESCRIPTORES}

Salud del anciano institucionalizado. Promoción de la salud. Hogares para ancianos.

"Extraído do trabalho de Conclusão de Curso "As engrenagens da saúde na terceira idade: um estudo com idosos asilados",Escola de Enfermagem Aurora de Afonso Costa da Universidade Federal Fluminense (EEAAC/UFF), 2006. ${ }^{1}$ Acadêmica do $9^{\circ}$ período do Curso de Graduação e Licenciatura em Enfermagem da Escola de Enfermagem Aurora de Afonso Costa da Universidade Federal Fluminense (EEAAC/UFF). Rio de Janeiro, RJ, Brasil. luana.pestana@uol.com.br ${ }^{2}$ Doutora em Enfermagem. Professora Adjunta do Departamento de Enfermagem Médico-Cirúrgica da EEAAC - UFF. Rio de Janeiro, RJ, Brasil. fatahelen@terra.com.br 


\section{INTRODUÇÃO}

A longevidade da população é um fenômeno mundial com inúmeras repercussões nos campos social e econômico. No Brasil, estima-se que a população idosa poderá alcançar 34 milhões de pessoas até 2025, o que representa, aproximadamente, $13 \%$ da população. Em 2000, o número de pessoas com 60 anos ou mais era de cerca de 14.536.029 contra 10.722.705 em $1991^{(1-2)}$.

Esse crescimento desperta-nos para uma consciência da velhice como uma questão social. 0 envelhecer faz parte da vida, corresponde a uma fase do curso da vida permeada por mudanças físicas, psicológicas e sociais que acometem cada pessoa, de forma muito peculiar. É um momento, em que, ponderando sobre a própria existência, a pessoa idosa percebe que alcançou muitos objetivos, mas também sofreu muitas perdas, das quais a saúde destaca-se como um dos aspectos mais afetados ${ }^{(3)}$. Essas mudanças advindas da velhice tendem a ser maximizadas de forma negativa em nossa sociedade, que segue um modelo capitalista, cuja base está centrada na valorização do homem de acordo com sua capacidade produtiva. 0 modelo capitalista fez com que a velhice passasse a ocupar um lugar marginalizado na existência humana, na medida em que a individualidade já teria os seus potenciais evolutivos e perderia, então, o seu valor social. Desse modo, não tendo mais a possibilidade de produção de riqueza, a veIhice perderia seu valor simbólico(4).

A partir, principalmente, da década de 80 , quando um boom da terceira idade acontece no Brasil, diferentes grupos de convivência passam a existir no país. A velhice deixa o status de doença e passa a ser vista como um processo natural do curso da vida dos seres humanos. Desde então, surge uma rede de instituições de prestação de serviços com o objetivo de prover aos idosos cuidados integrais à saúde. 0 asilo foi uma dessas primeiras instituições, preocupado em suprir necessidades básicas como alimentação e moradia aos idosos. Contudo, 0 atendimento nestas instituições é marcado por relatos de maus-tratos e abusos, o que exigiu do governo medidas drásticas em relação a esta situação. Desde 1996, quando 88 idosos faleceram num período de um mês em uma dessas instituições, uma CPI foi instaurada em 2001 revelando que a maioria dos asilos funciona de forma clandestina e que, certamente, aquele não era o único asilo que oferecia comida estragada, água contaminada e remédios vencidos. Corroborando com estes acontecimentos, a literatura científica nas áreas de geriatria e geron-tologia acerca da temática do idoso asilado reforça, muitas vezes, a questão do abandono, da exclusão social, da perda dos vínculos familiares, inatividade e improdutividade ${ }^{(5-7)}$.
Em resposta ao evidente envelhecimento populacional e à necessidade de se discutir ações integradas de promoção à saúde desta população, ocorre em Viena, em 1982, a I Assembléia Mundial sobre Envelhecimento da Organização das Nações Unidas (ONU), que, aprofundando conceitos como o de saúde, estabelecido em 1948, pela Organização M undial de Saúde (OMS) - que diz ser saúde o completo bem-estar físico, psíquico e social de um indivíduo e não somente a ausência de doenças ${ }^{(8)}$ - elegeu a qualidade de vida como algo tão importante quanto a longevidade, devendo ser fomentada pelos governos, famílias, sociedade e idosos. Esta assembléia influenciou o desdobramento das políticas de saúde para idosos no Brasi|(9).

Assim, essa realidade vem mudando, embora de forma lenta, através de políticas públicas como a Política Nacional de Saúde do Idoso, o Programa de Saúde do Idoso e o próprio Estatuto do Idoso, com propostas inovadoras como as universidades abertas da terceira idade, centros de convivência, grupos de atividades físicas e artísticas, suportes sociais como os centros-dia e casas-lar, com o objetivo principal de fortalecer o papel do idoso no que diz respeito à sua identidade, autonomia e cidadania(10-11). Em relação ao asilamento, existem ainda documentos mais específicos como a Portaria $n^{\circ} 810 / \mathrm{GM}$, de 22 de setembro de 1989, do M inistério da Saúde, que define Normas de Funcionamento de $\mathrm{Ca}$ sas de Repouso, Clínicas Geriátricas e Outras Instituições Destinadas ao Atendimento do idoso ${ }^{(22) ;}$ um $M$ anual de Instituições de Longa Permanência criado pela Associação Brasileira de Geriatria e Gerontologia ${ }^{(13)}$ e os capítulos VIII e IX - Título II, do Estatuto do Idoso(11).

A questão da institucionalização de idosos continua sendo um assunto delicado, visto que sua aceitação como alternativa de suporte social ainda não é consensual, embora seja indiscutível o aumento da demanda por este serviço. Desta forma, é necessário traçar o perfil do idoso, diferenciando aqueles que vivenciam um envelhecimento bem-sucedido daqueles que demandam atenção profissional especializada e, considerando estas variedades e especificidades, implementar uma forma de suporte adequado. Nesse sentido, os asilos, atualmente chamados de Instituições de Longa Permanência, representam uma dessas alternativas para um perfil específico de idosos. 0 que não é ainda uma realidade quando nas instituições brasileiras há uma grande procura por vagas, não só por parte dos idosos com alta dependência, mas também por idosos jovens, entre 60 e 65 anos, independentes, que foram alijados do mercado de trabalho e da proteção familiar, em decorrência das transformações socioeconômicas em curso na nossa sociedade ${ }^{(14)}$.

Assim, em virtude do envelhecimento populacional crescente, a atenção para com os aspectos de saúde do idoso tem crescido nas últimas décadas, sendo reconhecida como uma questão de saúde pública: 
[...] há um outro espaço fundamental a ser preenchido pela saúde pública. Trata-se do engajamento dos idosos como atores culturais visando o acolhimento dos idosos como atores nobres e essenciais na sociedade e a consideração da velhice como uma etapa da existência que pode ser desfrutada saudavelmente ${ }^{(15)}$.

Na área da Saúde Pública, a atenção ao idoso é abraçada pelo campo teórico da promoção da saúde, com premissas de um ideal de longevidade com qualidade de vida, reconhecendo a dificuldade de apreensão deste conceito por se tratar de um construto influenciado por aspectos históricos, culturais e de classe, e assumir diversas conotações. Trata-se de uma noção eminentemente humana que tem sido aproximada ao grau de satisfação encontrado na vida familiar, amorosa, social e ambiental e à própria estética existencial. Assim, qualidade de vida é a síntese de todos os bens que uma sociedade considera como seu padrão de conforto e bem-estar ${ }^{(16)}$.

Uma visão ampla do termo qualidade de vida comporta uma dimensão referida às condições objetivas de existência, ou patamar mínimo e universal de direitos básicos (alimentação, água potável, vestuário, trabalho, habitação, transporte, acesso a serviços, dentre outros), e em outro plano, aspectos subjetivos como amor, liberdade, realização pessoal, solidariedade, inserção social e felicidade ${ }^{(17)}$

Nesse sentido, considerando o idoso asilado e o conceito amplo de saúde e qualidade de vida apresentados, e, diante da realidade vivenciada pelos idosos no sistema asilar, emerge uma questão: qual é a situação de saúde do idoso asilado?

Este estudo, portanto, parte da premissa de que a saúde do idoso asilado nem sempre tem sido valorizada de forma a atender aos aspectos sociais e psicológicos, na perspectiva da promoção da saúde, o que tem contribuído, muitas vezes, para reforçar uma visão negativa do asilo, como um espaço que se limita apenas em fornecer condições objetivas para a sobrevivência. 0 asilo não é considerado como uma possibilidade de cuidado, mas como sinônimo de abandono, evidenciando a influência da visão estigmatizada que esta instituição desperta na sociedade ${ }^{(18)}$. Assim, à luz dessas considerações, sentimos a necessidade de conhecer de perto como os idosos vivem no asilo e como se consolida, para eles, o estar saudável, tendo como objetivos:

- Descrever a situação de saúde dos idosos que vivem em uma instituição asilar;

- Identificar como os idosos asilados percebem sua própria saúde.

\section{MÉTODO}

Trata-se de um estudo com abordagem qualitativa, cujo cenário foi um asilo filantrópico, localizado no Município do Rio de Janeiro (RJ), que durante esta pesquisa abri- gava 37 idosos, de ambos os sexos. As informações foram coletadas entre os meses de agosto e novembro de 2005 e os sujeitos do estudo foram dezessete idosos que viviam na instituição.

Para a seleção dos sujeitos utilizamos como critérios de inclusão a idade - pessoas com mais de 60 anos - de ambos os sexos, que tivessem interesse em participar do estudo. Como critérios de exclusão consideramos os idosos restritos ao leito, com idade inferior 60 anos e aqueles que possuíam comprometimentos cognitivos causados por algumas doenças como doença de Alzheimer, demência vascular, dentre outras.

A coleta de informações ocorreu em dois momentos: fase exploratória e fase de trabalho de campo. Na fase exploratória, procuramos caracterizar os sujeitos e o cenário da pesquisa, através de observação participante ${ }^{(19)}$ com registros em diário de campo, tendo como apoio um roteiro de observação que abrangeu aspectos como planta física e instalações, horários e rotinas da instituição e atividades realizadas pelos idosos.

No segundo momento, na fase de trabalho de campo, utilizamos como técnica de coleta de informações a entrevista semi-estruturada ${ }^{(19)}$ visando aprofundar os aspectos identificados através da observação participante. As entrevistas foram gravadas em fitas magnéticas, realizadas nas dependências do asilo, individualmente, em diferentes locais de acordo com a escolha dos entrevistados e, posteriormente, transcritas na íntegra para análise.

Seguindo as normas da Resolução 196/96(20), o protocolo de pesquisa foi aprovado pelo Comitê em Ética e Pesquisa do Hospital Universitário Antônio Pedro/RJ, Brasil e os sujeitos do estudo assinaram um Termo de Consentimento Livre e Esclarecido antes da realização das entrevistas (CEP 004/2006).

\section{RESULTADOS E DISCUSSÃO}

A análise das informações foi desenvolvida a partir da leitura do conteúdo das entrevistas. Adotou-se a análise temática que consiste em descobrir os núcleos de sentido que compõe uma comunicação cuja presença ou freqüência signifiquem alguma coisa para o objetivo analítico visado ${ }^{(21)}$. Os dados agrupados podem ser trabalhados para evidenciarem qualidades que, por sua semelhança, se constituirão em categorias de eventos, as quais podem ser reagrupadas em temas e sub-temas ${ }^{(19)}$. Assim, após a identificação dos temas comuns nas informações, foram elaboradas as seguintes categorias: Roda-viva: 0 movimento para o asilo, Viver no asilo: uma opção?, A dualidade do viver e perceber saúde.

\section{Roda Viva: 0 Movimento para 0 asilo}

A questão do asilamento no país tem despertado sentimentos de indignação em vários autores que a vêem como 
comprovada ação da sociedade que descarta os indivíduos no momento em que deixam de ser saudáveis, produtivos e utiliza um discurso controverso à sua integração ao meio social|(4,7,22).

Segundo pesquisa realizada em instituições asilares no Rio Grande do Sul(5), do total de 107 idosos entrevistados, $85,05 \%$ ainda possuem família, sendo $42,99 \%$ viúvos. Em outra pesquisa(6) realizada no município do Rio de Janeiro, envolvendo 775 idosos, também se observou que a maioria desses idosos é viúvo. 0 que sugere que a existência da família não garante a permanência do mesmo no núcleo familiar; ela estaria segura pela presença do cônjuge. A perda do cônjuge como fator determinante para 0 asilamento também foi retratada pelos sujeitos desse estudo, como ilustram as falas:

\begin{abstract}
Eu mesma procurei. Depois que meu marido faleceu morava sozinha num lugar e o senhorio vendeu a casa, tive que sair. Procurei outro lugar, mas com o que eu ganhava não dava pra pagar, aí eu comecei a procurar um lugar pra ficar e acabei aqui (A1).
\end{abstract}

Eu vivia com meu marido, vivia bem. Mas ele faleceu, aí eu fiquei sozinha (A2)

A perda do cônjuge provoca uma mudança com repercussões psicológicas e econômicas, principalmente quando se trata de um casal ajustado e sem apoio de familiares. A escala de Holmes ${ }^{(a)}$, citada pelo autor, indica que a morte do cônjuge ocupa o ponto máximo como fator de estresse, conjugando-se ao sentido de mudanças ${ }^{(23)}$.

Dentre as principais causas da inserção de idosos em instituições asilares destacam-se: condições precárias de saúde, distúrbios de comportamento, necessidade de reabilitação, falta de espaço físico para que seus familiares 0 abriguem, falta de recursos financeiros, abandono do idoso pela família que não consegue manter o idoso sob os seus cuidados (24).

As condições precárias de saúde geralmente levam as pessoas a perderem seus empregos, acarretando em falta de recursos. Doença e/ ou desemprego foram evidenciados nas falas:

[...]eu fiquei doente, diabético, e tive que parar de trabaIhar. Não poder trabalhar, né? Aí fica difícil! Essa é uma doença que o pessoal pensa que é boba, mas não é não, tem muitas coisas, prejudica as vistas e eu era caminhoneiro, precisava da visão boa (A3).

Eu fumava muito, tive um grave problema nas cordas vocais e por conta disso fui demitido. Três anos sem trabaIhar, começaram as brigas em casa, me separei...fiquei sozinho (A4).

(a)Escala para avaliação do estresse, criada na década de 70 , por Holmes e Rahe, que descobriram que o estresse produzido por importantes mudanças de vida era um fator de previsão de futuras doenças. São 43 mudanças possíveis (morte do cônjuge, aposentadoria, alterações da situação financeira, etc), atribuindo a cada uma um valor quanto à capacidade de provocar estresse, numa escala de 1 a 100. A perda do cônjuge ocupa o primeiro lugar, com 100 pontos.
Ilustrando esses dados, os idosos revelam a dificuldade das famílias em acolher seus idosos, seja por falta de espaço, de recursos ou de uma estrutura familiar que respeite 0 idoso:

Eu lembro que eu vim pra cá para a minha mãe não vir, pois só tinha uma vaga na casa da minha irmã, então eu disse: você fica com ela que eu vou pro asilo [...] minha filha mora nos EUA e a Rita trabalha, tem dois filhos, casa, aí ela me diz: mamãe, tô sem empregada, tenho duas crianças, tenho que trabalhar fora, quando eu venho é arrumando armário, fazendo comida para as crianças, supermercado, não posso ir te buscar (A5).

Fiquei desempregado, sem família. Fui morar com meu filho, mas minha nora reclamava muito. Um dia eu ouvi eles discutindo por minha causa e pedi ao meu filho que me levasse para um asilo, então ele me trouxe pra cá (A4).

A roda-viva, o movimento da vida dos idosos que caminham para o asilamento é permeado por aberrações políticas, sociais e biológicas. Nosso país está envelhecendo e convive com o paradoxo diário de ter pessoas morrendo de fome enquanto há um aumento das doenças crônicas não-transmissíveis, indicadoras de prosperidade e avanços tecnológicos para um país. A velhice tornouse objeto da política e as políticas públicas voltadas para os idosos são curativistas e imediatistas, sem efetividade em longo prazo. A dinâmica familiar, muitas vezes, fecha as portas para o idoso, as famílias nucleadas, os espaços físicos cada vez menores, as mulheres inseridas no mercado de trabalho que deixam seus filhos nas creches e seus idosos nos asilos.

\section{Viver no Asilo: uma opção?}

0 ato de viver não pode ser indiferente ao ser humano. Não é apenas um passar de tempo, é o passar do nosso tempo. A vida deve ser como um todo, senão jamais saberemos se estamos vivendo. Estar vivendo é estar caminhando num caminho que nos apresenta uma estrada a descobrir. Este caminhar é o reflexo daquilo que somos e que conquistamos, dependendo muito de nós mesmos ${ }^{(25)}$.

A passagem pelo asilo não é objetivo de nenhuma pessoa. Pode-se perceber que para os homens estar no asilo representa uma situação muito difícil:

Dá pra gostar?Você gostaria de ver seu pai aqui?Me pergunta se alguma vez eu pensei que acabaria aqui, você não guardou: seis filhos, três casamentos, três bisnetos e seis netos. Eu nunca vou me adaptar aqui, se eu pudesse eu iria embora, é que eu não posso, ganhando o que eu ganho, um salário mínimo, eu não posso alugar um quarto com banheiro. Se eu pudesse alugar um quarto eu ia morar sozinho e bem. Aqui não dá para dialogar com ninguém, tem de tudo aqui (A4).

Contrastam as mulheres com um discurso mais conformado, geralmente relacionado aos serviços prestados: 
Ah, eu gosto. É uma vida tranqüila, uma vida harmoniosa [...] eu sempre vivi muito bem e aqui não é mau, eu gosto sabe? A roupa de cama é limpa, troca toda semana, bem lavada e passadinha (A5).

Gosto, né? É melhor do que a pessoa ficar na rua, por aí, andando [...]eu consigo viver bem aqui, às vezes as pessoas me fazem uma grosseria, mas vou levando a vida (A2).

Para as mulheres, pode-se dizer que o asilo é um local definitivo, ao qual já se adaptaram, mesmo quando criticam com veemência algumas das práticas desenvolvidas na instituição. Os homens geralmente são mais críticos em relação à vida no asilo. Procuram mostrar que não estão adaptados e que não se adaptarão nunca ou, então, procuram deixar claro que suportam a instituição por uma razão bem específica [...] como por não ter outro lugar para ir ${ }^{(7)}$

Assim, os idosos vivem, tentam se adaptar. Diante desse desafio de buscar viver da melhor forma possível nessa realidade definitiva, as engrenagens social, mental e biológica nos conduzem para o objeto deste estudo, a saúde do idoso asilado. Viver e perceber sua própria saúde, que, neste cenário, parecem não estar em sintonia. Desta percepção emergiu a terceira categoria:

\section{A Dualidade do Viver e Perceber Saúde}

Desde o conceito de saúde definido pela OMS, em 1948, até os dias de hoje, a discussão sobre o processo saúdedoença tem evoluído muito. Hoje falamos de promoção da saúde, reconhecendo a natureza multifatorial da mesma, que envolve desde a alimentação, habitação, renda, emprego e é influenciada pelo contexto histórico e econômico, principalmente em uma sociedade capitalista como a nossa.

Pensar saúde, nos dia de hoje, transcende a visão de saúde como ausência de doenças. Ao estudar conceitos de saúde e doença você encontrará inúmeras correntes e classificações na busca incessante de responder a estas questões: o que é saúde? 0 que é doença? De fato, não é fácil responder a estes questionamentos, mesmo porque a resposta não é óbvia. Nenhuma das correntes de pensamento, seja alopata, filosófica, antropológica, holística ou transdiciplinar, consegue dar uma definição completa do fenômeno saúde-doença. Acreditamos que a dificuldade em definir saúde esteja ligada ao fato de que saúde não é um fenômeno estático, que ocorre da mesma maneira para todos. Enquanto processo individual, tanto a saúde quanto a doença estão muito mais relacionadas à representação que cada sujeito tem do que seja saúde e doença.

Para os idosos entrevistados, saúde está diretamente ligada à ausência de doenças. Apesar de a maioria ser portadora de alguma doença crônica não-transmissível, o importante é não estar apresentando sinais e sintomas destas. Mas, o discurso está sempre atrelado a poder trabalhar, estar lúcido, ter as necessidades básicas como alimentação, moradia, sono e repouso atendidas e manter os vínculos familiares. Para os idosos, o que importa é não ter doenças:

Saúde? É ter saúde, não cair doente (A6).

Acho que é o principal, pra nós, é ter saúde. Acho que sou único aqui que não tem doença, não tomo remédios. Levo uma vida em paz (A7).

Para as mulheres, saúde está relacionada diretamente à autonomia e lucidez. Ter as necessidades básicas atendidas, como afirmam as falas:

\begin{abstract}
Minha saúde é isso, tomar meus remédios todo dia, ter minhas coisas, meu sabão, minha alimentação direitinha, ter tudo limpinho, roupas, só isso (A2).
\end{abstract}

Saúde? Olha, eu me acho com saúde, tenho 90 anos, estou lúcida, enxergando e ouvindo bem. Tomo meu banho sozinha, não gosto de tá incomodando ninguém. Troco minha roupa, arrumo minhas coisas, faço questão (A1).

Mas, pensar em saúde para os idosos do estudo implica, também, em considerar 0 aspecto familiar:

\begin{abstract}
Ah, não sei filha te explicar... saúde...é ter saúde mesmo porque ando gripada, é ter alegria de viver, que eu tenho ainda, pensar com saudades nas minhas filhas e nos que já partiram, né? (A5).
\end{abstract}

Ai filha, eu não sei nem te explicar. Saúde é ficar em casa com família. No natal eu fui pra casa, fiquei quatro dias. $\mathrm{Na}$ hora de voltar pra cá foi muito ruim (fica em silêncio) (A9).

Diante da pergunta você se sente com saúde?, a maioria dos idosos respondeu que sim, mas saúde, neste momento, estava relacionada à ausência de doença:

Tá tudo bom. Lá na triagem a gente faz um monte de exames, aqui também fiz. É bom, né? O médico me passou uns remédios, mas disse que eu não tenho nada, é pra verme (A6).

Eu me sinto com saúde, não tenho doença (A7).

Eu me sinto com saúde, estou protegida aqui, tenho tudo que preciso, me consulto com o médico, trato minha pressão alta, o médico daqui é muito bom. Eu não me sinto doente não, só as minhas pernas que estão assim, vê? Tudo inchado, sinto dor aqui nas juntas...mas é coisa de velho, não tem jeito (A2).

Em contrapartida, ao serem perguntados quando se sentiam doentes, eles citaram a solidão, a improdutividade e o abandono como desencadeadores de um estado doente:

Eu me sentia doente assim quando tava sozinho, desempregado, por exemplo, aí é muito ruim, ficar sem trabalhar, sem ganhar nada (A3).

Rev Esc Enferm USP
$2008 ; 42(2): 268-75$. $\begin{aligned} & \text { As engrenagens da saúde na terceira idade: } \\ & \text { umw.ee.usp.br/reeuspl }\end{aligned}$


Eu me sinto doente do corpo e da alma...(silêncio)... o corpo envelhece, é normal, vem as doenças. Eu não precisava é ter doença na alma, essa a gente pode evitar. Eu fico muito triste sabe, primeiro porque a vida toda eu só pensei nos outros e acabei não reservando nada pra mim (lágrimas nos olhos) (A4).

Quando me sinto doente? Paixão... (silêncio)...quando me lembro do pessoal, saudades. Sinto o coração vazio, eu me sinto assim, coração partido, é o meu (A8).

Me sinto doente de ficar preso aqui, eu não consigo. Quero ficar com meus irmãos [...](A9).

Acreditamos ser apropriado referir, diante destas respostas a respeito de quando os idosos asilados se sentem doentes, que doenças como hipertensão arterial e diabetes estão diretamente relacionadas aos idosos, institucionalizados ou não. Contudo, a depressão parece estar particularmente em evidência nos asilos:

\section{[...] a depressão está muito freqüentemente vinculada às perdas, principalmente afetivas e as relacionadas a pa- péis familiares, laborais e sociais. No idoso asilado, as perdas são muitas, e isso justifica a grande incidência de estados depressivos e a limitação das possibilidades de prevenção(26).}

0 idoso asilado, relegado a uma espécie de isolamento e privado, muitas vezes, de suas atividades familiares e sociais, vive uma situação limitada e prejudicada e, mesmo que ele tenha monitoramento da sua saúde física, algo Ihe falta, que é a mobilidade social.

Assim, para os idosos do estudo, a concepção de saúde e ser saudável se apresenta de forma bastante particular de pessoa para pessoa. Estas concepções podem ser influenciadas por aspectos físicos, psicológicos, sociais, culturais e econômicos.

Dos dezessete idosos entrevistados, apenas dois não apresentavam uma doença crônica não-transmissível (DCNT). No entanto, a maioria se sentia com saúde e/ou não se sentia doente. A subjetividade dos conceitos acumulados durante a vida é que direciona para como a pessoa vê sua salubridade. A doença está relacionada ao mal estar físico e mental, além de condições precárias de vida e de saúde. A presença de agressores internos e externos reflete diretamente nas concepções de cada pessoa sobre doença e saúde. A satisfação pessoal é fundamental para definirmos se estamos bem ou não. E, quando não estamos nos sentindo bem, acabamos nos definindo como doentes:

Saúde é então compreendida por nós como forma de existir, o que implica compreender a melodia da vida, o ser feliz; doença é problema existencial, que reflete por sua vez, o como vivemos, afeta toda estrutura do existir humano, como ser com os outros e com o mundo ${ }^{(27)}$.

$\mathrm{Na}$ maturidade as pessoas expressam, cada uma ao seu modo, o que aprenderam e desenvolveram durante a vida, o que leva a um momento de reflexão. Com o passar dos anos nossos objetivos pessoais vão ficando mais claros e as coisas tendem a se tornar mais simples. E o idoso é quem está mais preparado para errar, acertar e consertar. Destas reflexões surgem novos objetivos a serem alcançados nesta fase singular de suas vidas - é a roda-viva - no seu movimento incessante de busca e aprendizado. Contudo, com base no que vimos e ouvimos dos idosos sujeitos deste estudo, a perda da autonomia, cidadania, identidade, papel social e vínculo familiar prejudicam esta busca interna, determinam e afirmam a morte civil(28) desses indivíduos.

\section{Ser contra ou a favor do asilo?}

Na consideração do ser humano idoso, [...] não há um lugar melhor para todos os idosos e sim, um lugar melhor para cada idoso. Cada um no seu mundo, seu espaço de viver melhor, com melhor viver das pessoas de seu grupo ${ }^{(29)}$.

Assim, o cuidado com a saúde é importante em qualquer etapa da vida e mais ainda em idade avançada. Não que o envelhecimento seja sinônimo de enfermidade, mas porque é nesta fase que as pessoas têm maior predisposição para desenvolver certos agravos, principalmente aquelas doenças classificadas como crônicas. Diante deste fator biológico, espera-se que grande parte dos idosos apresente alguma destas doenças, o que demanda em cuidados específicos, às vezes permanentes, de uma equipe multiprofissional e especializada para lidar com esta clientela, e isso inclui o asilo, local onde muitos idosos vivem e chegam diariamente.

\section{CONSIDERAÇÕES FINAIS}

A saúde dos idosos asilados, segundo suas concepções, é considerada satisfatória e está relacionada à ausência de dor, desconforto físico, pela segurança proporcionada pela instituição que garante comida, moradia e atendimento médico. As doenças referidas pelos sujeitos deste estudo estão entre aquelas consideradas típicas da velhice e que, se monitoradas e controladas, podem permitir uma maior longevidade. Por isso mesmo, é interessante ressaltar que a maioria dos idosos referiu não ter preocupação com a saúde no momento. As preocupações manifestadas dizem respeito principalmente às dores e sofrimentos, às perdas naturais, à falta da família, aos sentimentos de solidão e abandono que eles vivenciam no asilo.

Portanto, neste estudo, o fato social asilamento configurou-se principalmente pelo abandono, constituindo-se no seu principal motivo. As condições, muitas vezes precárias, encontradas nas instituições asilares, no que se refere à infra-estrutura, serviços prestados e recursos humanos só enfatizam essa situação. 0 idoso asilado é geralmente uma pessoa desmotivada para a vida, sem expectativas e com esperanças de retorno ao ambiente familiar. Além disso, ele ainda se vê na condição de ter 
que conviver com pessoas muito diferentes, às vezes até não idosas, com doenças incapacitantes, mentais, psiquiátricas e alcoolistas, o que torna 0 ambiente des-confortável. Assim, embora o contexto asilar atenda em parte ao idoso em suas necessidades básicas de moradia, alimentação e acompanhamento médico, por outro lado, nem sempre estimula a atividade do idoso que tende a se tornar mais introspectivo e isolado do convívio social.

Como qualquer pessoa, o idoso asilado necessita de atenção e cuidados e a participação de profissionais de diferentes áreas é fundamental para melhorar os serviços prestados e para qualificar o atendimento em benefício da saúde de cada pessoa. Por isso, sugere-se:

[...] atentar para as políticas sociais e de saúdes existentes; desenvolver trabalhos em casas asilares visando o conhecimento da legislação pertinente; orientar para a or-

\section{REFERÊNCIAS}

1. Instituto Brasileiro de Geografia e Estatística (IBGE). Censo demográfico 2000. Rio de Janeiro; 2000.

2. Davim RM B, Torres GV, Dantas SM M, Lima, VM. Estudo com idosos de instituições asilares no município de Natal/RN: características socioeconômicas e de saúde. Rev Lat Am Enferm. 2004;12(3):518-24.

3. Mendes MRSSB, Gusmão JL, Faro ACM, Leite RCBO. A situação social do idoso no Brasil: uma breve consideração. Acta Paul Enferm. 2005;4(18):422-6.

4. Veras RP. Terceira idade: gestão contemporânea em saúde. Rio de Janeiro: UNATI; 2002.

5. Cortelletti IA, Casara MB, Herédia VBM, organizadores. Idoso asilado: um estudo gerontológico. Caxias do Sul: EDUCS; 2004.

6. Duarte MJRS. Internação institucional do idoso: assistência à saúde em geriatria no setor público. Rev Enferm UERJ. 1993;1(1):3-13.

7. Debert GG. A reinvenção da velhice. São Paulo: EDUSP; 1999.

8. Organização das Nações Unidas (ONU). Assembléia mundial sobre envelhecimento: resolução 39/125. Viena; 1982.

9. Motta LB. Treinamento interdisciplinar em saúde do idoso: um modelo de programa adaptado às especificidades do envelhecimento [CD-ROM]. Rio de Janeiro: UNATI; 2005. (Série Livros Eletrônicos - Programas de Atenção ao Idoso).

10. Brasil. Lei n. 8.842, de 4 de janeiro de 1994. Dispõe sobre a Política Nacional do Idoso, cria o Conselho Nacional do Idoso e dá outras providências [legislação na Internet]. Brasília; 1994. [citado 2005 mar. 25]. Disponível em: http://www6.senado.gov.br/legislacao/ ListaPublicacoes. action? id =138955 ganização e o desenvolvimento de atividades físicas, intelectuais, religiosas, sociais que motivem o idoso tirando-o de sua inatividade, estimulando-o ao convívio social, ao desenvolvimento da linguagem e à busca de sentido para o seu dia-a-dia; criar novos núcleos de estudo e pesquisa sobre o envelhecimento $[\ldots]^{(5)}$.

Além disso, a sociedade deve pensar alternativas para superar as opções existentes e investir em iniciativas mais complexas de suporte social. Se tivéssemos disponíveis centros-dia, casas-lar, serviços domiciliares, oficinas abrigadas, entre outros, muito idosos residentes em asilos poderiam ser mantidos em seu ambiente sóciofamiliar. Para isso, há de se capacitar profissionais e voluntários, desenvolvendo atividades interdisciplinares e multidisciplinares, bem como estabelecer estratégias voltadas para a família do idoso, como preconizado nos programas e políticas públicas voltados para a terceira idade.

11. Brasil. Lei n. 10.741 , de $1^{\circ}$ de outubro de 2003. Dispõe sobre o Estatuto do Idoso e dá outras providências [legislação na Internet]. Brasília; 1994. [citado 2005 mar. 25]. Disponível em: http://www6.senado.gov.br/ legislacao/ ListaPublicacoes. action? id =237486.

12. Brasil. Ministério da Saúde. Portaria n. 810, de 22 de setembro de 1989. Dispõe sobre normas para o funcionamento de casas de repouso, clínicas geriátricas e outras instituições destinadas ao atendimento de idosos [legislação na Internet]. Brasília; 1989. [citado 2005 mar. 25]. Disponível em: http://www.mp.ba.gov.br/atuacao/ cidadania/geido/legislacao/portaria_810_89.asp.

13. Sociedade Brasileira de Geriatria e Gerontologia. Instituição de longa permanência para idosos: manual de funcionamento. São Paulo: SBGG; 2003.

14. Siqueira MEC, Moi RC. Estimulando a memória em instituições de longa permanência. In: Von Simson ORM, Néri $A L$, Cachioni $M$, organizadores. As múltiplas faces da velhice no Brasil. São Paulo: Alínea; 2003. p. 165-87.

15. M inayo MCS, organizadora. Os muitos Brasis: saúde e população na década de 80. São Paulo: Hucitec; 1995.

16. Minayo MCS, Hartz ZMA, Buss PM. Qualidade de vida e saúde: um debate necessário. Ciênc Saúde Coletiva. 2000;5(1):7-18.

17. Assis M. Promoção da saúde e envelhecimento: avaliação de uma experiência no ambulatório do Núcleo de Atenção ao Idoso da UnATI/UERJ [tese]. Rio de Janeiro: FIOCRUZ; 2004.

18. Santos NC, Meneghin P. Concepções dos alunos de graduação em enfermagem sobre 0 envelhecimento. Rev Esc Enferm USP. 2006;40(2):151-9.

19. Leopardi MT. Metodologia da pesquisa na saúde. Santa Maria: Pallotti; 2001. 
20. Conselho Nacional de Saúde. Resolução n. 196, de 10 de outubro de 1996. Dispõe sobre diretrizes e normas regulamentadoras de pesquisas envolvendo seres humanos. Bioética. 1996;4(2 Supl):15-25.

21. Minayo MCS. O desafio do conhecimento: pesquisa qualitativa em saúde. São Paulo: Hucitec; 1993.

22. Duarte MJRS. Atenção ao idoso: um problema de saúde pública na enfermagem. Rev Enferm UERJ. 2004;2(1): 100-11.

23. Bouk DA. Stress. Rev Bras Saúde Ocupac. 1988;1(1):23-6.

24. Telles Filho PCP, Petrilli Filho JF. Causas da inserção de idosos em uma instituição asilar. Esc Anna Nery Rev Enferm. 2002;1(6):119-33.
25. Gouvêa MAC. Terceira idade, ainda tempo de semear. Petrópolis: Vozes; 2002.

26. Bigarella RL. Depressão no idoso. In: Hekman PRW, Hekman M, Bigarella R, Senger J, Consoni P, organizadores. Atualidades em geriatria. Porto Alegre: SBGGRS; 1996. p. 8-14.

27. Polar YN, Kalegari DRG, Jouclas VMG. Saúde do adulto: um enfoque multidisciplinar. Curitiba: Pinha; 1997.

28. Goffman E. Manicômios, prisões e conventos. 7a ed. São Paulo: Perspectiva; 2005.

29. Erdmann AL. Tecnologia em enfermagem geriátrica e gerontológica. Texto Contexto Enferm.1997;6(2):151-4. 